\title{
Large-scale ion generation for precipitation of atmospheric aerosols
}

\author{
Shaoxiang $\mathrm{Ma}^{1}{ }^{1}$, He Cheng ${ }^{1} \star$, Jiacheng $\mathrm{Li}^{1}$, Maoyuan $\mathrm{Xu}^{1}$, Dawei Liu ${ }^{1}$, and Kostya Ostrikov ${ }^{2}$ \\ ${ }^{1}$ State Key Lab of Advanced Electromagnetic Engineering and Technology, School of Electrical and Electronic Engineering, \\ Huazhong University of Science and Technology, Wuhan, Hubei 430074, China \\ ${ }^{2}$ Institute for Future Environments and School of Chemistry and Physics, Queensland University of Technology, \\ Brisbane, Queensland 4000, Australia \\ * These authors contributed equally to this work.
}

Correspondence: Dawei Liu (liudw@ @ust.edu.cn)

Received: 17 January 2020 - Discussion started: 24 April 2020

Revised: 18 July 2020 - Accepted: 28 July 2020 - Published: 16 October 2020

\begin{abstract}
Artificial rain is explored as a remedy for climate change caused farmland drought and bushfires. Increasing the ion density in the open air is an efficient way to generate charged nuclei from atmospheric aerosols and induce precipitation or eliminate fog. Here we report on the development of a large commercial-installation-scale atmospheric ion generator based on corona plasma discharges, experimental monitoring, and numerical modeling of the parameters and range of the atmospheric ions, as well as the application of the generated ions to produce charged aerosols and induce precipitation at the scale of a large cloud chamber. The coverage area of the ions generated by the large corona discharge installation with the $7.2 \mathrm{~km}$ long wire electrode and applied voltage of $-90 \mathrm{kV}$ is studied under prevailing weather conditions including wind direction and speed. By synergizing over 300000 localized corona discharge points, we demonstrate a substantial decrease in the decay of ions compared to a single corona discharge point in the open air, leading to large-scale $(30 \mathrm{~m} \times 23 \mathrm{~m} \times 90 \mathrm{~m})$ ion coverage. Once aerosols combine with the generated ions, charged nuclei are produced. Higher wind speed has led to larger areas covered by the plasma-generated ions. The cloud chamber experiments (relative humidity $130 \pm 10 \%$ ) suggest that charged aerosols generated by ions with a density of $\sim 10^{4} \mathrm{~cm}^{-3}$ can accelerate the settlement of moisture by $38 \%$. These results are promising for the development of large-scale installations for the effective localized control of atmospheric phenomena.
\end{abstract}

\section{Introduction}

The water cycle and rainfall on the Earth are affected by climate change, causing widespread droughts around the world (Dai, 2013; Trenberth et al., 2014). Recently, more and more forest fires have happened in North America, Australia and China. Besides that, the lack of water in many parts of Asia and Africa seriously influences local agriculture, industry and human health (Jolly et al., 2015; Lesk et al., 2016). Artificial rain has been used widely in many countries to alleviate drought problems by enhancing precipitation. Artificial rain is commonly realized by dispersing substances, such as silver iodide, dry ice and table salts, which act as cloud condensation nuclei and alter the physicochemical processes within the cloud.

It is well known that the ions generated by galactic cosmic rays in the atmosphere directly affect changes in the cloudiness of the Earth (Carslaw et al., 2002; Pierce and Adams, 2009). An experiment in a Wilson chamber suggested that ions generated by radioactive materials act as condensation nuclei under supersaturation conditions (Yang et al., 2018). Nielsen et al. (2011) found that charged nuclei could remain in the condensation phase even when the relative humidity is less than $100 \%$ (Nielsen et al., 2011). This is why plasmaand laser-based techniques have been employed to generate charged nuclei in the open air to try to realize rain enhancement or, alternatively, fog elimination (Henin et al., 2009; Khain et al., 2004; Tan et al., 2016). 
Ideally, the effects (e.g., precipitation of atmospheric aerosols) of plasma-based methods should be delivered over the areas of small- to medium-sized farmlands. Indeed, it appears appealing to install, for example, a large-scale corona plasma discharge system on top of a hill and distribute the generated ions using the wind. Corona plasma discharges can release high-concentration ion fluxes, which can not only be transported to a large area by the upwind slope airflow, but also effectively interact with atmospheric aerosols, thereby generating charged nuclei needed to induce or enhance water precipitation in areas along the downwind direction. However, there are formidable science and technological challenges to implement it in practice. First, we are not aware of any systematic experimental and theoretical studies on the generation efficiency of ions, the coverage area of ions and the effect of wind on ion transport at the relevant scale of atmospheric ion-generating installations. Second, the high efficiency of ion generation in the laboratory does not necessarily translate into a similar performance at scale. One reason is destructive interference of multiple corona discharges along the same plasma-generating wire, which is addressed in this work. Third, there are no reliable estimates of the volumes at which ions are generated at concentrations that are appropriate for atmospheric aerosol precipitation. Fourth, reliable quantitative estimates of the significance of the effects of plasma-generated ions on moisture precipitation under realworld conditions are very limited, if available at all. Fifth, quantitative effects of the real-world wind on ion coverage at the large installation scale are eagerly anticipated by the community.

In this work, we address all the above issues and report on the coverage area of ions generated by a large corona discharge system with a $7.2 \mathrm{~km}$ long wire electrode and applied voltage of $-90 \mathrm{kV}$. The vertical and horizontal distributions of ions in the downwind direction are measured under realistic weather conditions. Numerical models of corona discharge and ion transport are developed. The results of numerical modeling are consistent with the experiment results and indicate that the ions produced by the plasma discharge device may affect aerosol precipitation over large areas depending on the direction and speed of the wind. The effects of the plasma-generated ions on moisture precipitation are studied experimentally at the scale of a large cloud chamber.

\section{Methods}

\subsection{Corona discharge installation and ion measurements}

Both positive and negative corona discharge can be used to increase the ion density in the open air. Under similar conditions of the electric circuit the loss of the positive corona is greater than that of the negative corona at the same applied voltage. Because the negative corona curve is flatter and since larger negative corona currents can be obtained, the negative corona is much better adapted for applications such as fog elimination and electrical precipitation than the positive corona (Sawant et al., 2012; Strong, 1913)

The wire electrode is a low-cost and high-efficiency plasma source configuration, especially for the large-scale corona discharge system. For a wire electrode radius within the range of 100 to $1000 \mu \mathrm{m}$, the plasma thickness increases with increasing wire radius. Larger wires can generate more electrons; however, the electron energy decreases due to the lower electric field near a larger wire (Chen and Davidson, 2003). Stainless-steel stranded wire is suitable wire electrode material considering durability and stability.

Electrons generated by negative corona discharge attach to electronegative gas molecules (such as, $\mathrm{O}_{2}$ ) to generate negative ions $\left(\mathrm{O}_{2}^{-}\right)$. Recombination of electrons with positive ions is negligible. Therefore, ionization competes primarily with electron attachment. Ionization predominates over electron attachment and new electrons are generated. The rate of ionization balances the rate of electron attachment at the reduced electric field of $120 \mathrm{Td}\left(1 \mathrm{Td}=10^{-21} \mathrm{Vm}^{2}\right)$. Beyond this ionization boundary, attachment dominates over ionization, and the electron density decreases gradually as the electric field decreases (Chen and Davidson, 2003; Kossyi et al., 1992; Lowke and Morrow, 1994). In the region away from the electrode, because of the absence of the electric field, the charged particles, including electrons and ions, perform a faster decay through electron-ion and ion-ion recombination with background charged particles (Xiong et al., 2010)

The large corona discharge system employed in this study has the floor area $\sim 11304 \mathrm{~m}^{2}$ (Fig. 1a, b). Six poles each with the height of $20 \mathrm{~m}$ supporting the $7.2 \mathrm{~km}$ long wire electrode are erected vertically and arranged in a regular hexagon array. The wire electrodes are divided into two layers at the height of 20 and $15 \mathrm{~m}$, i.e., with $5 \mathrm{~m}$ separation between the layers. There are 10 wire electrodes in each layer, and the horizontal distance between the wires is $50 \mathrm{~cm}$ to avoid mutual interference. The stainless-steel wire has six strands and a diameter of $1 \mathrm{~mm}$. The high-voltage DC power supply is Technix 44-2015, which can monitor the output voltage and current value in real time.

Figure 1c shows a satellite image of the test zone. The hexagon shows the large-scale corona discharge system. The red points show the locations of the ion density measurements. The hydrogen balloon carrying the ion counter (Air Ion Counter) is used to measure the vertical $(5-50 \mathrm{~m})$ and horizontal $(20-50 \mathrm{~m})$ ion density in the downwind direction as shown in Fig. 1d. The horizontal distance between the hydrogen balloon measurement and the wire electrode is $20 \mathrm{~m}$ to ensure the safety of the experiment. The image of the corona discharge on the wire electrode is taken by a digital camera (Nikon D800) with the exposure time of $2 \mathrm{~s}$. Optical emission spectroscopy (OES) of the negative corona discharge on the wire electrode with the applied voltage of 

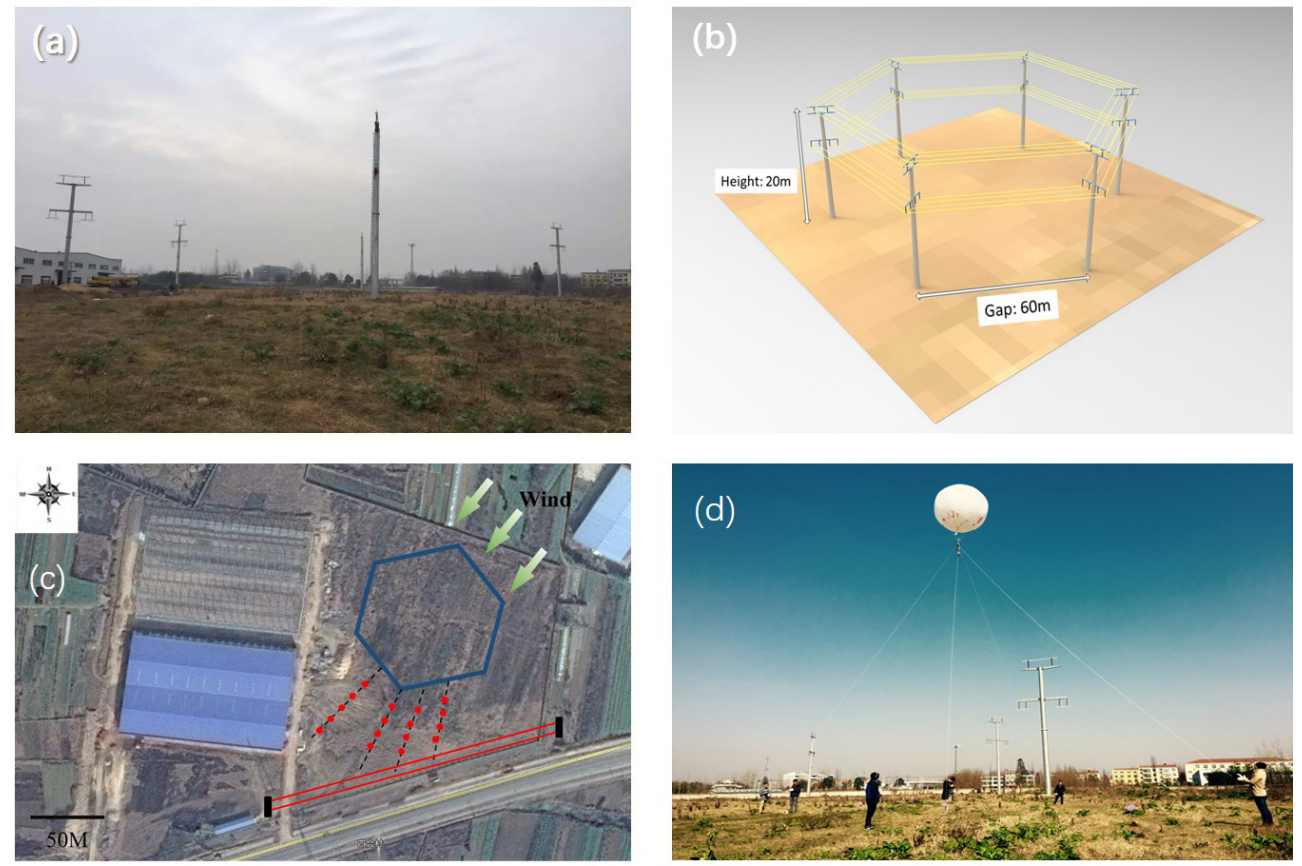

Figure 1. Large-scale installation of ion generation for the precipitation of atmospheric aerosols using over 300000 corona plasma discharges. (a) The large-scale corona discharge system consists of six poles and $7.2 \mathrm{~km}$ electric wires. (b) The design diagram of the hexagonal discharge arrays. (c) A satellite image of the test zone (taken from https://map.baidu.com, last access: 29 December 2019). The hexagon shows the corona plasma discharge system. The red points show the locations of ion density measurements. (d) The hydrogen balloon carried the ion density measurement device.

$-40 \mathrm{kV}$ is measured by an optical spectrometer (Ocean optics USB4000+).

\subsection{Ion transport model}

A 2D numerical model is used to the study the distribution of ions within $1 \mathrm{~m}$ from the wire electrode. The model used in this study extends the existing models (He et al., 2013; Liu et al., 2012, 2014a, b) to model the relevant phenomena at the relevant scales. The model solves the Poisson's equation and the transport equations for neutral and charged species as a function of time. The number density of each species is obtained by solving the continuity equation. The electric field is obtained by solving the Poisson's equation. The electron energy is calculated by the electron energy conservation equation.

The transient advection-diffusion reaction in Eq. (1) is used to study the effect of wind on the transport of ions (Albani et al., 2015; Ashrafi et al., 2017; Schleder and Martins, 2016):

$\frac{\partial c}{\partial t}+u \nabla c=\nabla(K \nabla c)-\lambda c, \quad c=c(x, y, z, t)$,

where $c$ is the crosswind-integrated concentration of ions, $t$ is time, $u$ is the wind speed, $\nabla=\left(\frac{\partial}{\partial x}, \frac{\partial}{\partial y}, \frac{\partial}{\partial z}\right), x$ is the horizontal downwind direction, $y$ is the horizontal radial direction, $z$ is the vertical direction, $K$ is the eddy diffusivity, which is calculated from the meteorological data of the test location ( $\sim 4.82 \mathrm{~m}^{2} \mathrm{~s}^{-1}$; Albani et al., 2015), and $\lambda$ is the decay constant, which is calculated based on the recombination of positive ions and electrons $\left(\sim 1.5113 \mathrm{~s}^{-1}\right)$ (Sakiyama et al., 2012).

The eddy diffusion $K$ represents the diffusion of ions under the influence of the turbulent state of the atmosphere. During stable conditions, the maximum value of eddy diffusivity decreases with increasing stability. In stable conditions, the height at which turbulence maintained is limited by the destruction of turbulent kinetic energy by negative buoyancy (Ulke, 2000), while in unstable conditions, the maximum value of eddy diffusivity increases with growing instability characterized by increasing values of $H_{\mathrm{A}} / L\left(H_{\mathrm{A}}\right.$ is the ABL height, $L$ is the Monin-Obukhov length).

The decay constant $\lambda$ represents the decay of ions due to the recombination reactions between charged particles, such as $\mathrm{e}+\mathrm{N}_{2}^{+} \rightarrow \mathrm{N}_{2}, \quad \mathrm{e}+\mathrm{O}_{2}^{+} \rightarrow 2 \mathrm{O}$ and $\mathrm{O}_{2}^{-}+\mathrm{N}_{2}^{+}+\mathrm{N}_{2} \rightarrow 2 \mathrm{O}+2 \mathrm{~N}_{2}$. According to our simulation results, the combination of numerous corona discharge points actually decreases the decay of ions generated by a single corona discharge point in the open air. 


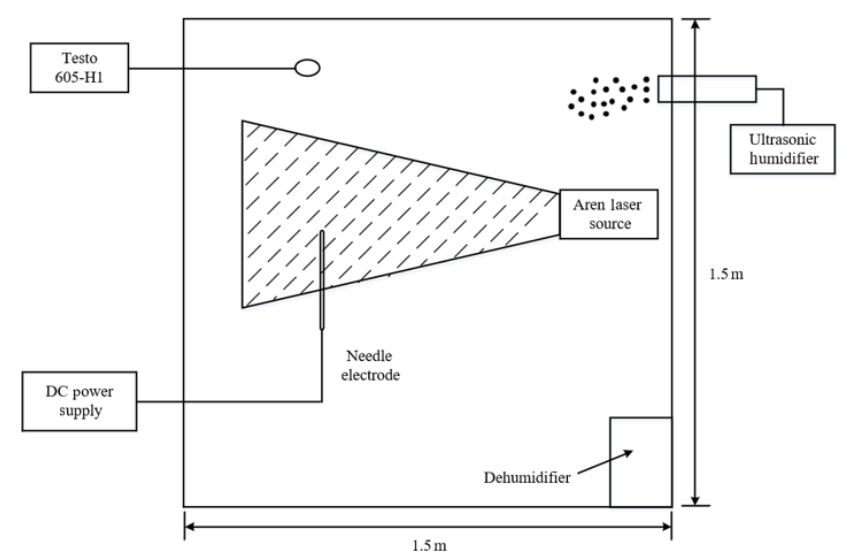

Figure 2. Schematic of the $6.75 \mathrm{~m}^{3}$ cloud chamber used for the ionenhanced precipitation.

\subsection{Cloud chamber experiments}

The cloud chamber used to study enhanced water condensation by ions has the size of $3 \mathrm{~m} \times 1.5 \mathrm{~m} \times 1.5 \mathrm{~m}$ (Fig. 2). The temperature inside the chamber is $2 \pm 1^{\circ}$ during the experiment (Testo 605-H1). The dehumidifier (Gree DH40EF) and ultrasonic humidifier (Midea SC4E40) are used to control the humidity supersaturation at $130 \pm 10 \%$. The laser illuminator (YGL01, planar laser source) is used to light up the cloud chamber. The changing process of droplets is recorded by a digital camera (Nikon D800) with a microscopic lens. Finally, an acceptor with a cross section of $10 \mathrm{~cm}^{2}$ is placed at the bottom of the cloud chamber to accept the settlement of moisture.

\section{Results and discussion}

\subsection{Corona discharges and ion generation}

The applied voltage on the wire electrode with the length of $7.2 \mathrm{~km}$ is $-90 \mathrm{kV}$ (Fig. 1), and the discharge current is $0.3 \mathrm{~mA}$, so the plasma power is $27 \mathrm{~W}$. Figure $3 \mathrm{~b}$ shows that there are more than 20 corona discharge points on the wire electrode with the length of $1 \mathrm{~m}$. Because the distance between the camera and the wire electrode is only $2 \mathrm{~m}$, the applied voltage is therefore $-40 \mathrm{kV}$ to ensure experimental safety. Although the six strands of stainless-steel wire have good anti-stretching and anti-bending properties, there are numerous small peaks on the wires, which help ignite corona discharges. Consequently, the minimum inception voltage of the corona discharge on the wire is only $-15 \mathrm{kV}$. More corona discharge points are thus expected for the field experiment with the applied voltage of $-90 \mathrm{kV}$.

Figure 3 shows the OES data of the corona discharge on the wire electrode. The brightest peaks can be seen around $315,337,350$ and $380 \mathrm{~nm}$, which are attributed to the nitrogen second positive electronic transition $\left(\mathrm{N}_{2}\left(\mathrm{C}^{3} \Pi_{u^{-}}\right.\right.$

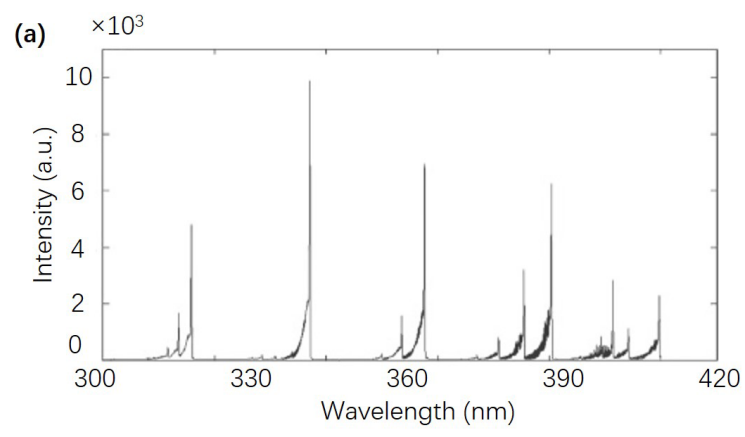

(b)

Figure 3. (a) Nitrogen species dominate the optical emission spectra (shown between 300 and $400 \mathrm{~nm}$ here) from the negative corona discharge on the wire electrode generated with the applied voltage of $-40 \mathrm{kV}$. (b) An image of corona discharge on the wire $(1 \mathrm{~m}$ length, $-40 \mathrm{kV})$. The exposure time of the image is $0.5 \mathrm{~s}$. The wire (diameter of $1 \mathrm{~mm}$ ) was composed of six strands of wire.

$\left.\mathrm{B}^{3} \Pi_{g}\right)$ ) and its family of vibrational- and rotational-level sub-transitions (Antao et al., 2009; Hu et al., 2013; Wang et al., 2013; Zou et al., 2019). The OES of OH and O radicals is quite low compared with $\mathrm{N}_{2}$ species (Gan et al., 2019).

For the negative corona discharge, the plasma region only occupies a very small portion of the space around the power electrode; negative ions occupy the region outside the plasma region (Chen and Davidson, 2003; Riba et al., 2018; Yao et al., 2019; Zhang et al., 2019). Figure 4a shows the boundary of the plasma region defined as the position at which the reduced electric field (electric field divided by neutral density, $\mathrm{E} / \mathrm{N})$ of $80 \mathrm{Td}\left(1 \mathrm{Td}=10^{-21} \mathrm{Vm}^{2}\right)$ is $0.1 \mathrm{~cm}$ from the electrode (Chen and Davidson, 2003). Therefore, the negative ion density at the boundary of the plasma region $(\sim 1 \mathrm{~cm}$ from the electrode, reduced electric field $\sim 10 \mathrm{Td}$ ) is chosen as the source density of negative ions for each case.

As the applied voltage amplitude increases from 30 to $90 \mathrm{kV}$, the source density at $1 \mathrm{~cm}$ from the single discharge point increases from $1.1 \times 10^{8}$ to $3.9 \times 10^{8} \mathrm{~cm}^{-3}$, and the density at $1 \mathrm{~m}$ from the single discharge point increases from $1.8 \times 10^{6}$ to $8 \times 10^{6} \mathrm{~cm}^{-3}$ (Fig. 4 b). In addition, Fig. $4 \mathrm{c} \mathrm{sug}-$ gests that the ion density in the whole simulation domain increases with increasing applied voltage amplitude.

\subsection{Ion transport}

Figure 5 shows the effect of the wind on the transport of ions generated by a single corona discharge point. The ion density at the plasma boundary is chosen as the source density. The ion density measured at the position $1 \mathrm{~m}$ from the electrode is consistent with the numerical result calculated by Eq. (1). As the wind speed increases from 0 to $5.7 \mathrm{~m} \mathrm{~s}^{-1}$, the ion density at $1 \mathrm{~m}$ increases from $2.5 \times 10^{6}$ to $4 \times 10^{6} \mathrm{~cm}^{-3}$, and the density at $3 \mathrm{~m}$ increases from $3.2 \times 10^{4}$ to $2 \times 10^{5} \mathrm{~cm}^{-3}$, which 
(a)

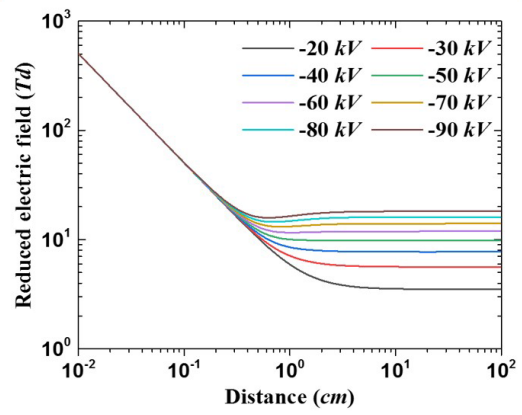

(b)

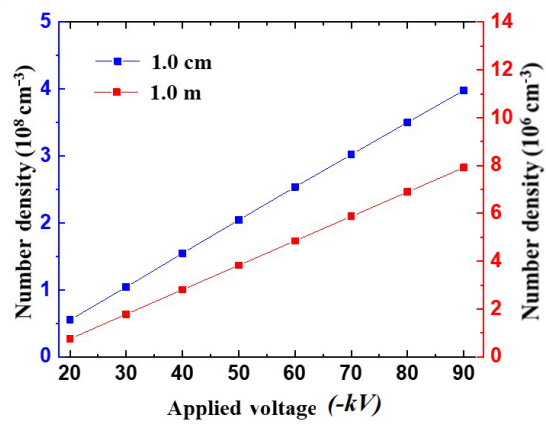

(c)
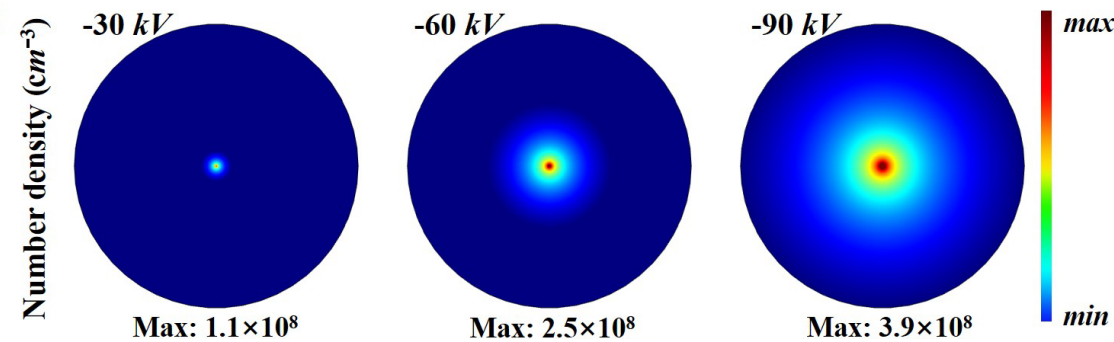

Figure 4. The increasing applied voltage enhances the ion output capacity of the corona discharge source. (a) The electric field from the center as a function of applied voltage. (b) The ion density at $1 \mathrm{~cm}$ (blue line) and $1 \mathrm{~m}$ (red line) from the center as a function of applied voltage. (c) The distribution of ions generated by a single corona discharge point (simulation). The center is the corona discharge point. The radius of the big blue circle is $1 \mathrm{~m}$.

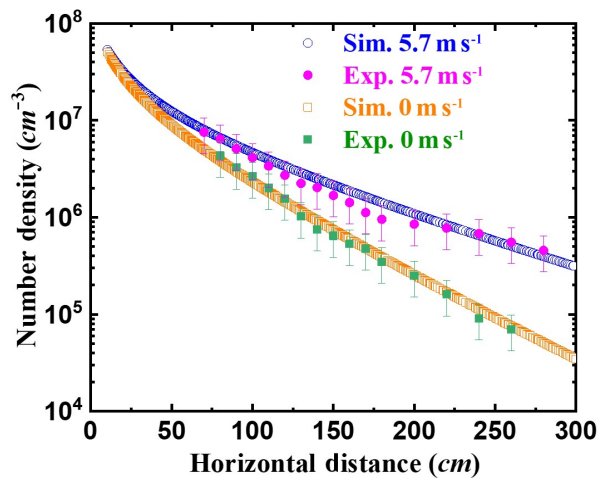

Figure 5. The effect of wind on the distribution of ions generated by a single corona discharge point (indoor tests). Wind speed at 0 and $5.7 \mathrm{~m} \mathrm{~s}^{-1}$. The applied voltage on the wire electrode was $-40 \mathrm{kV}$. The experiment measurement data are plotted as error bars. The simulation data are plotted as hollow symbols.

indicates that diffusivity dominates the ion movement in the low electric field region, and the wind convection can substantially enhance ion transport (Albani and Albani, 2019; Ashrafi et al., 2017; Hosseini and Stockie, 2016; Schleder and Martins, 2016)

Figure 6a shows the coverage range (horizontal / vertical $(x / z)$ direction) of negative ions generated by the large corona discharge system shown in Fig. 1. In order to ensure safety, the ion counter carried by the balloon starts recording the negative ion density at a position $20 \mathrm{~m}$ from the wire electrode. The ion density decreases from $5 \times 10^{5}$ to $8 \times 10^{3} \mathrm{~cm}^{-3}$ as the distance from the wire electrode increases from 20 to $30 \mathrm{~m}$. Afterwards, the ion density decreases to the background value as the horizontal distance increases to $40 \mathrm{~m}$. The relatively high density of $10^{4} \mathrm{~cm}^{-3}$ at the horizontal position of $50 \mathrm{~m}$ can be attributed to random enhanced transport by gusts. The width of the coverage area in the radial direction was $90 \mathrm{~m}$. Therefore, the whole coverage volume was approximately $30 \mathrm{~m}$ (long) $\times 23 \mathrm{~m}$ (height) $\times 90 \mathrm{~m}$ (width). The overall discharge system configuration is an hexagon with a side length of $60 \mathrm{~m}$ (Fig. 1); therefore, the distance between two opposite sides is $103.92 \mathrm{~m}$. The radial measurement range is $\sim 95 \mathrm{~m}$ with the consideration of surrounding buildings. Therefore, the width of $90 \mathrm{~m}$ is obtained. Because $90 \mathrm{~m}$ is less than $103.92 \mathrm{~m}$, decay at the boundary is avoided in this range. The coverage volume of $30 \mathrm{~m} \times 23 \mathrm{~m} \times 90 \mathrm{~m}$ is a relatively conservative range. Aerosols can combine with the ions generated in this volume, thus creating a large number of charged nuclei within the volume (Anon, 2000; Bricard et al., 1968; Harrison, 2000; Harrison and Carslaw, 2003; Keefe et al., 1959).

It is interesting to note that the ion density at $20 \mathrm{~m}$ from the single corona discharge point is only $10^{2} \mathrm{~cm}^{-3}$ (Fig. 6c), which is only $0.02 \%$ of the ion density generated by the large corona discharge system (Fig. 6a). Figure $3 b$ suggests the presence of more than 45 corona discharge points along the $1 \mathrm{~m}$ long wire electrode when the applied voltage is $-40 \mathrm{kV}$, 

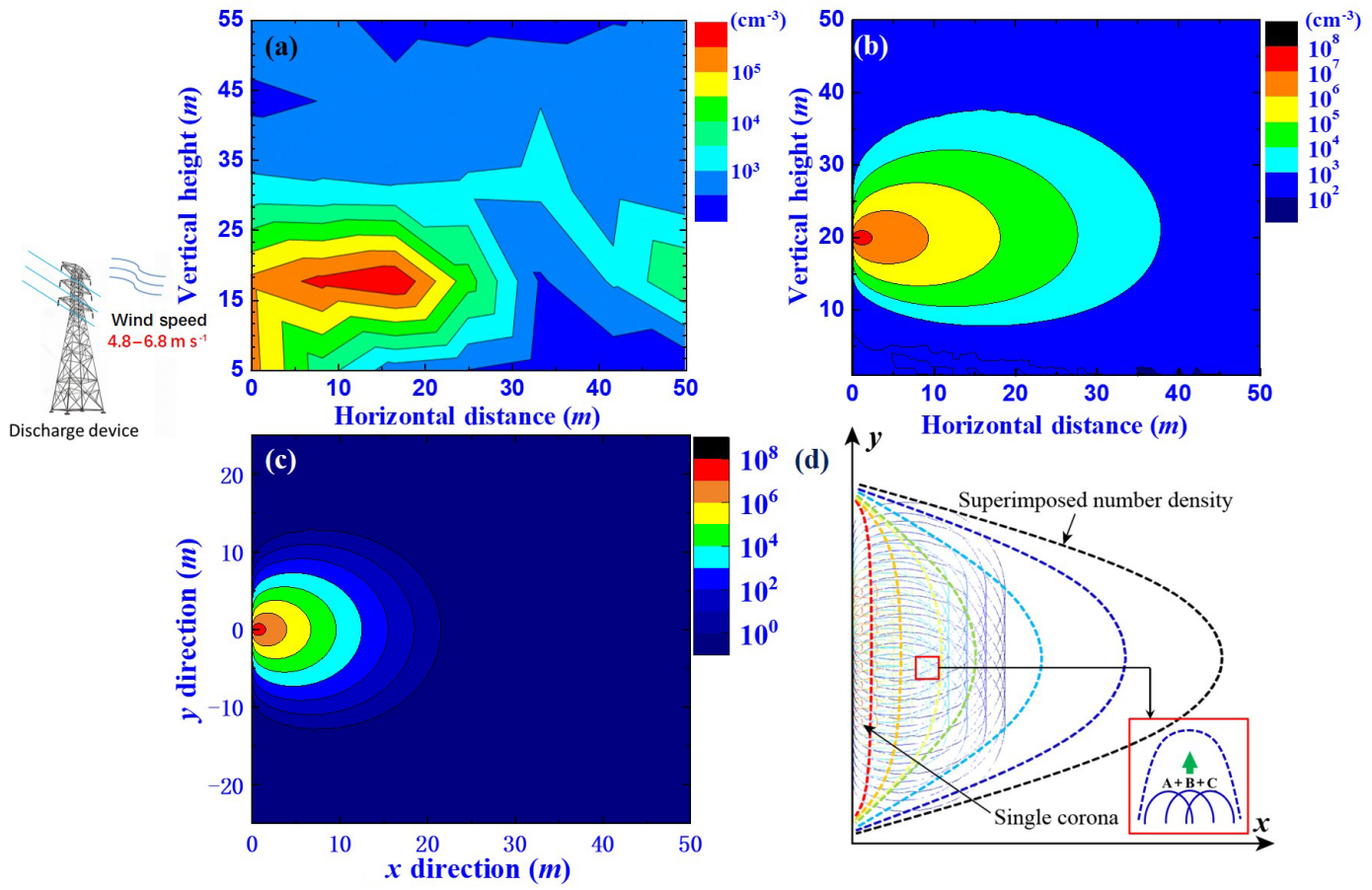

Figure 6. The coverage area of the large corona discharge system is a combination of the coverage areas of a very large number of corona discharge points. (a) The ion density distribution in the vertical direction and downwind direction (experimental measurement, applied voltage $-90 \mathrm{kV}$ ). (b) The ion density distribution in the vertical direction and downwind direction (simulation, $z$ axis, vertical direction, $x$ axis, horizontal direction). (c) The ion density distribution of a single corona discharge point $(-90 \mathrm{kV})$ in the horizontal direction $(x-y$ axis). (d) The combination of ions generated by multiple corona discharge points resulted in a high negative ion density in the open air. The dashed colored lines from red to black suggest the ion density decreases as the distance from the wire electrode increases. The inset indicates that the combination of ions generated by three corona discharge sources increases the coverage of ions substantially.

and the average distance between corona discharge points is only $2.5 \mathrm{~cm}$. For the large corona discharge system with the $7.2 \mathrm{~km}$ long wire electrode and applied voltage of $-90 \mathrm{kV}$, the number of corona discharge points is expected to be at least $3.2 \times 10^{5}\left(45 \times 7.2 \times 10^{3}\right)$.

Figure $6 \mathrm{~d}$ shows the collective transport efficiency of ions generated by the many corona discharge points. Because the distance between the corona discharge points is in the centimeter range and the coverage area of each corona discharge point is $25 \mathrm{~m}$ ( $x$ direction) $\times 30 \mathrm{~m}$ ( $y$ direction) (Fig. 6c), the overlap of the coverage areas results in a high ion density in the open air.

The comparison between the experimental (Fig. 6a) and simulation (Fig. 6c) results suggests that the combination of numerous corona discharge points actually decreases the decay of ions generated by a single corona discharge point in the open air and substantially increases the outward transport capacity of ions in the large corona discharge system. In the simulation model, by decreasing the decay constant $\lambda 4.533$ times, Eq. (1) provides a similar coverage area as measured in the experiment (compare Fig. 6a and b).

Because the large corona discharge system may be set up on a mountaintop, e.g., with an altitude of around $4000 \mathrm{~m}$ (Farr and Chadwick, 2012; Mu et al., 2007; Shiyin et al.,
2003; Zhou and Yang, 2010), the effect of the wind and applied voltage on the coverage area of the large corona discharge system is also studied by the numerical model.

Figure $7 \mathrm{a}-\mathrm{c}$ suggest that as the wind speed increases from 2.89 to $12.5 \mathrm{~m} \mathrm{~s}^{-1}$, the axial length of the coverage area (ion density $\sim 10^{4} \mathrm{~cm}^{-3}$ ) increases from 26 to $73 \mathrm{~m}$. Figure $7 \mathrm{~d}-\mathrm{f}$ suggest that as the amplitude of the applied voltage increases from 60 to $180 \mathrm{kV}$, the axial length of the coverage area increases from 34 to $46 \mathrm{~m}$. The comparison between the effects of the wind and applied voltage indicates that increasing transfer flux with faster wind speed is a more efficient way to increase the coverage area of the large corona discharge system. The larger coverage area can facilitate the generation of charged nuclei, which eventually realize rain enhancement and fog elimination (Frederick and Tinsley, 2018; Tinsley and Zhou, 2015; Zhang et al., 2018a).

\subsection{Ion-enhanced precipitation}

A cloud chamber is used to study the enhancement of droplet growth by ions before the completion of the large-scale corona discharge system. The corona discharge on the needle electrode (applied voltage of $-23 \mathrm{kV}$ ) provides an environment with the ion density of $1.2 \times 10^{5}-2 \times 10^{4} \mathrm{~cm}^{-3}$ in the 


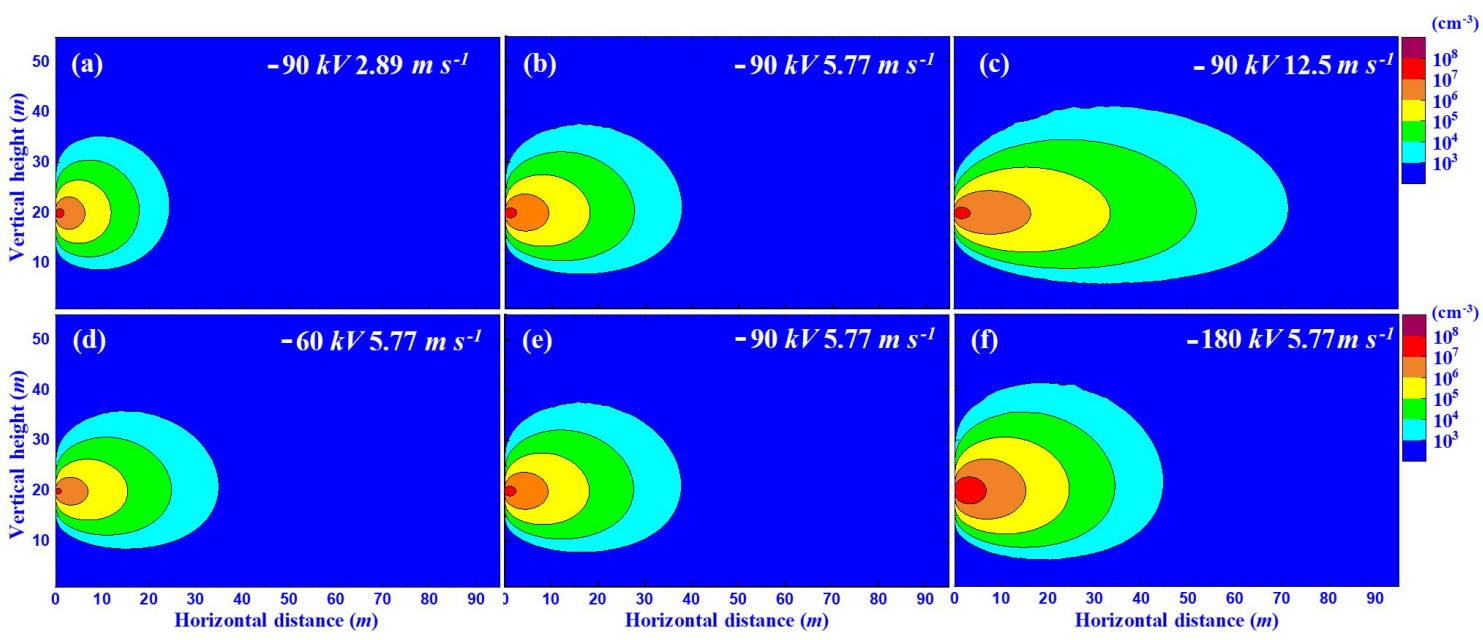

Figure 7. Increasing applied voltage and wind speed can enlarge the coverage area of the ion source. The effect of wind on the ion distribution in the field (numerical results) at (a) $-90 \mathrm{kV}$ and $2.89 \mathrm{~m} \mathrm{~s}^{-1}$ (wind speed), (b) $-90 \mathrm{kV}$ and $5.77 \mathrm{~m} \mathrm{~s}^{-1}$, and (c) $-90 \mathrm{kV}^{2}$ and $12.5 \mathrm{~m} \mathrm{~s}{ }^{-1}$. The effect of wind on the ion distribution in the field (numerical results) at (d) $-60 \mathrm{kV}$, (e) $-90 \mathrm{kV}$ and (f) $-180 \mathrm{kV}$.

cloud chamber, which corresponds to the ion density in the region $30-35 \mathrm{~m}$ from the wire electrode (Fig. 6a). The high ion density in the cloud chamber facilitates aerosol charging. Aerosols (diameter $>0.7 \mu \mathrm{m}$ ) are mainly charged by the drift of ions on the electric field lines intersecting the surface of aerosols. The diffusion of ions to the surface of aerosols also contributes to aerosol charging (Jidenko and Borra, 2012).

The size distributions of droplets in the natural settling case and the ion-enhanced settling case are compared in Fig. 8. The droplet sizes are distributed mainly in the range of $10-40 \mu \mathrm{m}$ for the case of natural settling. Charged aerosols are generated through the combination of ions and aerosols. Besides conventional forces such as thermophoretic and diffusiophoretic forces, electric forces contribute to collisions between small charged aerosols and uncharged aerosols (Cherrier et al., 2017; Hashino et al., 2014; Luan et al., 2019; Roy et al., 2019; Wang and Pruppacher, 1977; Zhang et al., 2018b; Zhang and Tinsley, 2017). Charged aerosols can induce an image charge on large uncharged aerosols, and the consequent electric force is the short-range attractive force. Previous simulation results suggest that charged aerosols can increase the collision rate between aerosols by 1 to 3 orders of magnitude (Tan et al., 2016). Therefore, the droplet sizes are distributed in the range of $50-80 \mu \mathrm{m}$ for the case of charged aerosol settling. However, uncharged aerosols in the natural settling case (control group) can only cause a limited increase in the particle size distribution. The large droplets generated by charged droplets can capture a large number of small aerosols during their settling process and cause faster settling of supersaturated water vapor in the cloud chamber. Figure $8 \mathrm{~d}$ indicates that the settling amount of moisture induced by charged aerosols is $38 \%$ higher than in the natural settling case (control group) at $10 \mathrm{~min}$ after the start of the experiment.

\subsection{Techno-economic estimates}

As a simple techno-economic estimate, we note that the cost of the large corona discharge system including the DC power supply, six poles, and wires with a length of $7.2 \mathrm{~km}$ was less than 250000 Chinese Yuan (CNY). The low-maintenance solar and wind power system (estimated cost of CNY 50 000) can provide a continuous supply of renewable energy for the corona plasma discharge system. This energy supply system can be installed on-site and operated off the grid. Even considering the high construction cost of the system on mid-altitude mountains of about CNY 200000 , the total cost of the installation was approximately CNY 500000 . Importantly, this cost is well below the typical cost of cloud seeding carried out in China (at least CNY 1 million) to generate artificial rain. After the completion of the setup and real-world testing and optimization of the large-scale corona discharge installation, it may have an effect on rainfall in the downwind area. A similar approach can be used for fog elimination applications, for example along airport runways. Importantly, the plasma system can be switched on to instantly generate ions and then switched off to also instantly cease ion production whenever the wind direction or other atmospheric conditions change. This important feature of plasma adds an additional level of flexibility in the commercial operation of the system.

\subsection{Future work}

We have stressed that precipitation by charged particles actually depends on the relations between temperature, humidity supersaturation and ion concentration. More indoor experiments within a larger temperature range and humidity range can provide more detailed data to determine the relations above. Future outdoor experiments on high mountains will 

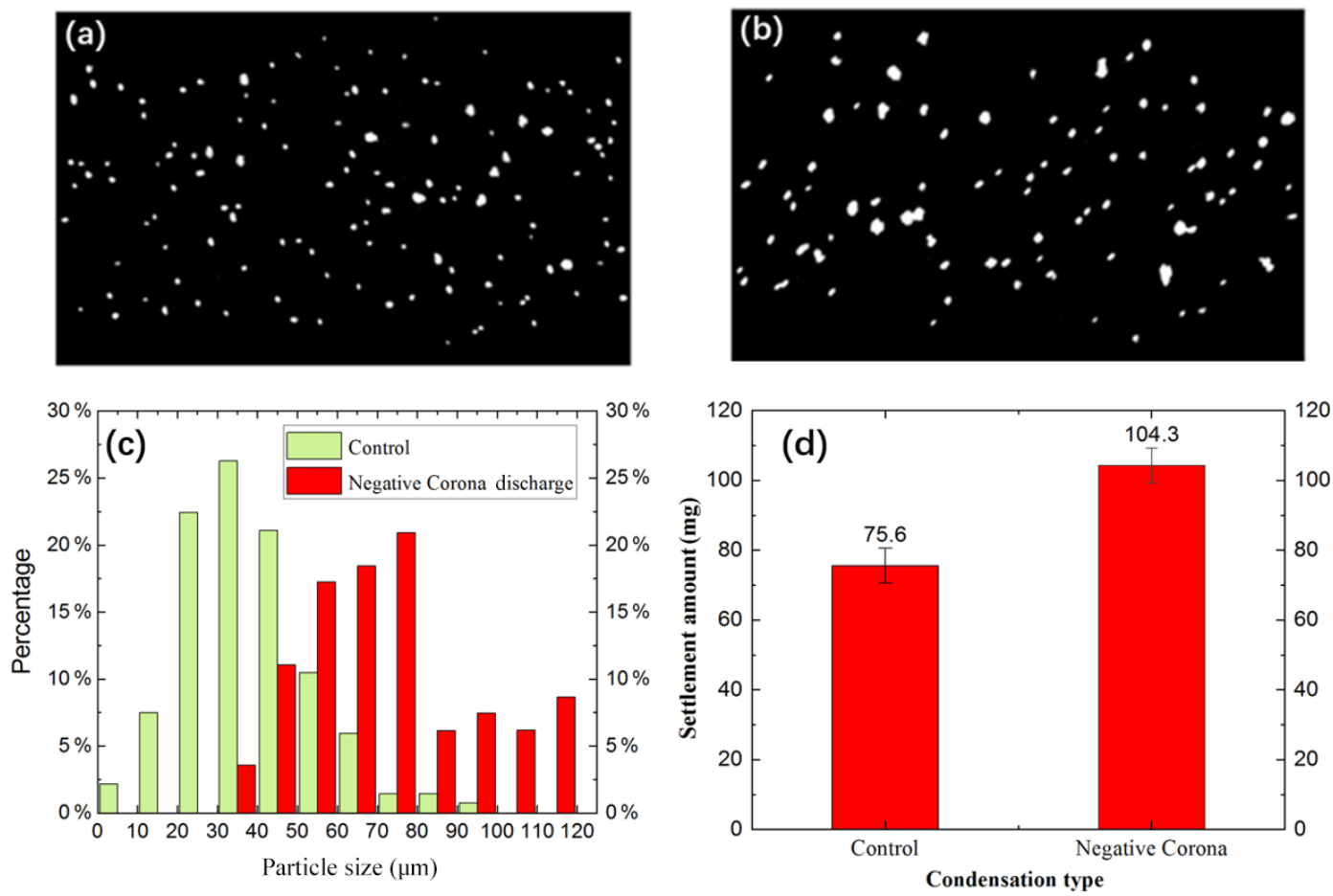

Figure 8. The ions generated by a corona discharge source enhance the condensation of aerosols. Shown here is a photo of aerosols in the light path of a laser for the case of the (a) control group and (b) the enhanced condensation group by ions. The photo was taken 5 min after the experiment started. (c) The particle size distribution of aerosols in the cloud chamber for the control group and negative corona discharge group (calculated according to $\mathbf{a}$ and $\mathbf{b}$ ). (d) The ions generated by a corona discharge source enhance the settlement of moisture. The settlement of moisture for the control and negative corona discharge groups on the acceptor 10 min after the experiment started.

determine the effect of wind, temperature and terrain on the ion coverage and precipitation range. Although wire icing is a challenge for outdoor experiments, a reliable ice-melting system can solve this problem.

\section{Conclusion and implications}

To summarize, a large-scale corona plasma discharge system was installed to analyze the production and coverage area of negative ions that are capable of inducing the precipitation of atmospheric aerosols in the downwind direction. Nitrogen species dominated the optical emission spectra of the negative corona discharges. The corona discharge was found to perform as a stable ion source with the density of $\sim 10^{8} \mathrm{~cm}^{-3}$. The coverage area of the ions was dramatically improved by using over 300000 corona discharge points, which also reduced the common destructive interference leading to the decay of ion concentrations in the open air, thereby dramatically increasing the outward ion transport capacity of the large-scale corona plasma discharge installation. As a result, a large ion coverage area $(30 \mathrm{~m} \times 23 \mathrm{~m} \times 90 \mathrm{~m})$ has been achieved experimentally and validated by numerical calculations. Faster wind speed was a more efficient way to increase the ion coverage area. The cloud chamber experiment confirms that the charged aerosols generated by ions can accelerate the settlement of moisture by $38 \%$. These results indicate that a large-scale corona discharge installation can indeed increase the ion density within a certain region. Furthermore, ion-induced charged aerosols may realistically trigger water precipitation or, alternatively, fog elimination. Since the latter effects were studied using our large-scale cloud chamber laboratory system, systematic field studies under real-world conditions are warranted to optimize the complex processes involved in the ioninduced precipitation of atmospheric aerosols under prevailing weather conditions.

Data availability. Data are available from the corresponding author upon reasonable request.

Author contributions. SM and HC made equal contributions. DL initiated and supervised the study. JL and MX performed experimental studies. DL and KO collaborated on interpreting the results. DL prepared the paper with significant contributions from HC, JL and $\mathrm{KO}$. 
Competing interests. The authors declare that they have no conflict of interest.

Acknowledgements. This work was supported by the National Key Research and Development Plan of China (grant no. 2016YFC0401001).

Financial support. This research has been supported by the National Key Research and Development Plan of China (grant no. 2016YFC0401001).

Review statement. This paper was edited by Fangqun Yu and reviewed by two anonymous referees.

\section{References}

Albani, R. A. S. and Albani, V. V. L.: Tikhonov-type regularization and the finite element method applied to point source estimation in the atmosphere, Atmos. Environ., 211, 69-78, https://doi.org/10.1016/j.atmosenv.2019.04.063, 2019.

Albani, R. A. S., Duda, F. P.. and Pimentel, L. C. G.: On the modeling of atmospheric pollutant dispersion during a diurnal cycle: A finite element study, Atmos. Environ., 118, 19-27, https://doi.org/10.1016/j.atmosenv.2015.07.036, 2015.

Anon: Estimation of the agglomeration coefficient of bipolarcharged aerosol particles, J. Electrostat., 48, 93-101, doi:10.1016/S0304-3886(99)00053-4, 2000.

Antao, D. S., Staack, D. A., Fridman, A., and Farouk, B.: Atmospheric pressure dc corona discharges: operating regimes and potential applications, Plasma Sources Sci. Technol., 18, 035016, https://doi.org/10.1088/0963-0252/18/3/035016, 2009.

Ashrafi, K., Orkomi, A. A., and Motlagh, M. S.: Direct effect of atmospheric turbulence on plume rise in a neutral atmosphere, Atmos. Pollut. Res., 8, 640-651, https://doi.org/10.1016/j.apr.2017.01.001, 2017.

Bricard, J., Billard, F., and Madelaine, G.: Formation and evolution of nuclei of condensation that appear in air initially free of aerosols, J. Geophys. Res., 73, 4487-4496, https://doi.org/10.1029/JB073i014p04487, 1968.

Carslaw, K. S., Harrison, R. G., and Kirkby, J.: Cosmic Rays, Clouds, and Climate, Science, 298, 1732-1737, https://doi.org/10.1126/science.1076964, 2002.

Chen, J. and Davidson, J. H.: Model of the Negative DC Corona Plasma: Comparison to the Positive DC Corona Plasma, Plasma Chemistry and Plasma Processing, 23, 83-102, https://doi.org/10.1023/A:1022468803203, 2003.

Cherrier, G., Belut, E., Gerardin, F., Tanière, A., and Rimbert, N.: Aerosol particles scavenging by a droplet: Microphysical modeling in the Greenfield gap, Atmos. Environ., 166, 519-530, https://doi.org/10.1016/j.atmosenv.2017.07.052, 2017.

Dai, A.: Increasing drought under global warming in observations and models, Nat. Clim Change, 3, 52-58, https://doi.org/10.1038/nclimate1633, 2013.

Farr, T. G. and Chadwick, O. A.: Geomorphic processes and remote sensing signatures of alluvial fans in the Kun Lun
Mountains, China, J. Geophys. Res.-Planet, 101, 23091-23100, https://doi.org/10.1029/96JE01603, 2012.

Frederick, J. E. and Tinsley, B. A.: The response of longwave radiation at the South Pole to electrical and magnetic variations: Links to meteorological generators and the solar wind, J. Atmos. Sol.-Terr. Phys., 179, 214-224, https://doi.org/10.1016/j.jastp.2018.08.003, 2018.

Gan, L., Duan, J., Zhang, S., Liu, X., Poorun, D., Liu, X., Lu, X., Duan, X., Liu, D., and Chen, H.: Cold atmospheric plasma ameliorates imiquimod-induced psoriasiform dermatitis in mice by mediating antiproliferative effects, Free Radical Res., 53, 269280, https://doi.org/10.1080/10715762.2018.1564920, 2019.

Harrison, R. G.: Cloud Formation and the Possible Significance of Charge for Atmospheric Condensation and Ice Nuclei, Space Sci. Rev., 94, 381-396, https://doi.org/10.1023/A:1026708415235, 2000.

Harrison, R. G. and Carslaw, K. S.: Ion-aerosol-cloud processes in the lower atmosphere, Rev. Geophys., 41, 1012, https://doi.org/10.1029/2002RG000114, 2003.

Hashino, T., Chiruta, M., Polzin, D., Kubicek, A., and Wang, P. K.: Numerical simulation of the flow fields around falling ice crystals with inclined orientation and the hydrodynamic torque, Atmos. Res., 150, 79-96, https://doi.org/10.1016/j.atmosres.2014.07.003, 2014.

He, J., Hu, J., Liu, D., and Zhang, Y.-T.: Experimental and numerical study on the optimization of pulse-modulated radiofrequency discharges, Plasma Sources Sci. Technol., 22, 035008, https://doi.org/10.1088/0963-0252/22/3/035008, 2013.

Henin, S., Petit, Y., Kiselev, D., Kasparian, J., and Wolf, J.-P.: Contribution of water droplets to charge release by laser filaments in air, Appl. Phys. Lett., 95, 091107, https://doi.org/10.1063/1.3220066, 2009.

Hosseini, B. and Stockie, J. M.: Bayesian estimation of airborne fugitive emissions using a Gaussian plume model, Atmos. Environ., 141, 122-138, https://doi.org/10.1016/j.atmosenv.2016.06.046, 2016.

Hu, J. T., Wang, J. G., Liu, X. Y., Liu, D. W., Lu, X. P., Shi, J. J., and Ostrikov, K.: Effect of a floating electrode on a plasma jet, Phys. Plasmas, 20, 083516, https://doi.org/10.1063/1.4817954, 2013.

Jidenko, N. and Borra, J. P.: Self-cleaning, maintenancefree aerosol filter by non-thermal plasma at atmospheric pressure, J. Hazard. Mater., 235, 237-245, https://doi.org/10.1016/j.jhazmat.2012.07.055, 2012.

Jolly, W. M., Cochrane, M. A., Freeborn, P. H., Holden, Z. A., Brown, T. J., Williamson, G. J., and Bowman, D. M. J. S.: Climate-induced variations in global wildfire danger from 1979 to 2013, Nat. Commun., 6, 1-11, https://doi.org/10.1038/ncomms8537, 2015.

Keefe, D., Nolan, P. J., and Rich, T. A.: Charge Equilibrium in Aerosols According to the Boltzmann Law, P. Roy. Irish Acad. A., 60, 27-45, 1959.

Khain, A., Arkhipov, V., Pinsky, M., Feldman, Y., and Ryabov, Y.: Rain enhancement and fog elimination by seeding with charged droplets, Part I: Ttheory and numerical simulations, J. Appl. Meteorol., 43, 1513-1529, https://doi.org/10.1175/JAM2131.1, 2004.

Kossyi, I. A., Kostinsky, A. Y., Matveyev, A. A., and Silakov, V. P.: Kinetic scheme of the non-equilibrium discharge in nitrogen- 
oxygen mixtures, Plasma Sources Sci. Technol., 1, 207-220, https://doi.org/10.1088/0963-0252/1/3/011, 1992.

Lesk, C., Rowhani, P., and Ramankutty, N.: Influence of extreme weather disasters on global crop production, Nature, 529, 84-87, https://doi.org/10.1038/nature16467, 2016.

Liu, X. Y., Hu, J. T., Liu, J. H., Xiong, Z. L., Liu, D. W., Lu, X. P., and Shi, J. J.: The discharge mode transition and $\mathrm{O}(5 \mathrm{p} 1)$ production mechanism of pulsed radio frequency capacitively coupled plasma, Appl. Phys. Lett., 101, 043705, https://doi.org/10.1063/1.4733662, 2012.

Liu, X. Y., Pei, X. K., Lu, X. P., and Liu, D. W.: Numerical and experimental study on a pulsed-dc plasma jet, Plasma Sources Sci. T., 23, 035007, https://doi.org/10.1088/0963-0252/23/3/035007, 2014a.

Liu, X. Y., Pei, X. K., Ostrikov, K., Lu, X. P., and Liu, D. W.: The production mechanisms of $\mathrm{OH}$ radicals in a pulsed direct current plasma jet, Phys. Plasmas, 21, 093513, https://doi.org/10.1063/1.4895496, 2014b.

Lowke, J. J. and Morrow, R.: Theory of electric corona including the role of plasma chemistry, Pure Appl. Chem., 66, 1287-1294, https://doi.org/10.1351/pac199466061287, 1994.

Luan, T., Guo, X., Zhang, T., and Guo, L.: Below-Cloud Aerosol Scavenging by Different-Intensity Rains in Beijing City, J. Meteorol. Res., 33, 126-137, https://doi.org/10.1007/s13351-0198079-0, 2019.

Mu, Y., Pang, X., Quan, J., and Zhang, X.: Atmospheric carbonyl compounds in Chinese background area: A remote mountain of the Qinghai-Tibetan Plateau, J. Geophys. Res.-Atmos., 112, D22302, https://doi.org/10.1029/2006JD008211, 2007.

Nielsen, J. K., Maus, C., Rzesanke, D., and Leisner, T.: Charge induced stability of water droplets in subsaturated environment, Atmos. Chem. Phys., 11, 2031-2037, https://doi.org/10.5194/acp-11-2031-2011, 2011.

Pierce, J. R. and Adams, P. J.: Can cosmic rays affect cloud condensation nuclei by altering new particle formation rates?, Geophys. Res. Lett., 36, L09820, https://doi.org/10.1029/2009GL037946, 2009.

Riba, J.-R., Morosini, A., and Capelli, F.: Comparative Study of AC and Positive and Negative DC Visual Corona for Sphere-Plane Gaps in Atmospheric Air, Energies, 11, 2671, https://doi.org/10.3390/en11102671, 2018.

Roy, A., Chatterjee, A., Ghosh, A., Das, S. K., Ghosh, S. K., and Raha, S.: Below-cloud scavenging of size-segregated aerosols and its effect on rainwater acidity and nutrient deposition: A long-term (2009-2018) and real-time observation over eastern Himalaya, Sci. Total Environ., 674, 223-233, https://doi.org/10.1016/j.scitotenv.2019.04.165, 2019.

Sakiyama, Y., Graves, D. B., Chang, H.-W., Shimizu, T., and Morfill, G. E.: Plasma chemistry model of surface microdischarge in humid air and dynamics of reactive neutral species, J. Phys. D, 45, 425201, https://doi.org/10.1088/0022-3727/45/42/425201, 2012.

Sawant, V. S., Meena, G. S., and Jadhav, D. B.: Effect of Negative Air Ions on Fog and Smoke, Aerosol Air Qual. Res., 12, 10071015, https://doi.org/10.4209/aaqr.2011.11.0214, 2012.

Schleder, A. M. and Martins, M. R.: Experimental data and CFD performance for $\mathrm{CO}_{2}$ cloud dispersion analysis, Journal of Loss Prevention in the Process Industries, 43, 688-699, https://doi.org/10.1016/j.jlp.2016.03.027, 2016.
Shiyin, L., Wenxin, S., Yongping, S., and Gang, L.: Glacier changes since the Little Ice Age maximum in the western Qilian Shan, northwest China, and consequences of glacier runoff for water supply, J. Glaciol., 49, 117-124, https://doi.org/10.3189/172756503781830926, 2003.

Strong, W. W.: The Positive and the Negative Corona and Electrical Precipitation, Transactions of the American Institute of Electrical Engineers, 2, 1755-1765, https://doi.org/10.1109/TAIEE.1913.4765093, 1913.

Tan, X., Qiu, Y., Yang, Y., Liu, D., Lu, X., and Pan, Y.: Enhanced Growth of Single Droplet by Control of Equivalent Charge on Droplet, IEEE T. Plasma Sci., 99, 1-5, https://doi.org/10.1109/TPS.2016.2608832, 2016.

Tinsley, B. A. and Zhou, L.: Parameterization of aerosol scavenging due to atmospheric ionization, J. Geophys. Res.-Atmos., 120, 8389-8410, https://doi.org/10.1002/2014JD023016, 2015.

Trenberth, K. E., Dai, A., Schrier, G., van der, Jones, P. D., Barichivich, J., Briffa, K. R., and Sheffield, J.: Global warming and changes in drought, Nat. Clim Change, 4, 17-22, https://doi.org/10.1038/nclimate2067, 2014.

Ulke, A. G.: New turbulent parameterization for a dispersion model in the atmospheric boundary layer, Atmos. Environ., 34, 10291042, https://doi.org/10.1016/S1352-2310(99)00378-7, 2000.

Wang, J. G., Liu, X. Y., Liu, D. W., Lu, X. P., and Zhang, Y. T.: Mathematical model of gas plasma applied to chronic wounds, Phys. Plasmas, 20, 113507, https://doi.org/10.1063/1.4826955, 2013.

Wang, P. K. and Pruppacher, H. R.: An Experimental Determination of the Efficiency with Which Aerosol Particles are Collected by Water Drops in Subsaturated Air, J. Atmos. Sci., 34, 1664-1669, https://doi.org/10.1175/15200469(1977)034<1664:AEDOTE>2.0.CO;2, 1977.

Xiong, Q., Lu, X., Xian, Y., Liu, J., Zou, C., Xiong, Z., Gong, W., Chen, K., Pei, X., Zou, F., Hu, J., Jiang, Z., and Pan, Y.: Experimental investigations on the propagation of the plasma jet in the open air, J. Appl. Phys., 107, 073302, https://doi.org/10.1063/1.3369538, 2010.

Yang, Y., Tan, X., Liu, D., Lu, X., Zhao, C., Lu, J., and Pan, Y.: Corona Discharge-Induced Rain and Snow Formation in Air, IEEE T. Plasma Sci., 46, 1786-1792, https://doi.org/10.1109/TPS.2018.2820200, 2018.

Yao, X., Jiang, N., Li, J., Lu, N., Shang, K., and Wu, Y.: An improved corona discharge ignited by oxide cathodes with high secondary electron emission for toluene degradation, Chem. Eng. J., 362, 339-348, https://doi.org/10.1016/j.cej.2018.12.151, 2019.

Zhang, B., He, J., and Ji, Y.: Prediction of average mobility of ions from corona discharge in air with respect to pressure, humidity and temperature, IEEE Trns. Dielectr. Electr. Insul., 26, 14031410, https://doi.org/10.1109/TDEI.2019.008001, 2019.

Zhang, L. and Tinsley, B. A.: Parameterization of aerosol scavenging due to atmospheric ionization under varying relative humidity, J. Geophys. Res.-Atmos., 122, 5330-5350, https://doi.org/10.1002/2016JD026255, 2017.

Zhang, L., Tinsley, B. A., and Zhou, L.: Parameterization of InCloud Aerosol Scavenging Due to Atmospheric Ionization: Part 3. Effects of Varying Droplet Radius, J. Geophys. Res.-Atmos., 123, 10546-10567, https://doi.org/10.1029/2018JD028840, 2018 a. 
Zhang, L., Tinsley, B. A., and Zhou, L.: Parameterization of InCloud Aerosol Scavenging Due to Atmospheric Ionization: Part 3. Effects of Varying Droplet Radius, J. Geophys. Res.-Atmos., 123, 10546-10567, https://doi.org/10.1029/2018JD028840, 2018 b.

Zhou, X. and Yang, J.: A Novel Solar Thermal Power Plant with Floating Chimney Stiffened onto a Mountainside and Potential of the Power Generation in China's Deserts, Heat Transfer Engineering, 30, 400-407, https://doi.org/10.1080/01457630802414813, 2010.
Zou, X., Xu, M., Pan, S., Gan, L., Zhang, S., Chen, H., Liu, D., Lu, X., and Ostrikov, K. K.: Plasma Activated Oil: Fast Production, Reactivity, Stability, and Wound Healing Application, ACS Biomater. Sci. Eng., 5, 1611-1622, https://doi.org/10.1021/acsbiomaterials.9b00125, 2019. 